\title{
COMPARISON OF WAVE-CURRENT INTERACTION FORMULATION USING THE POLCOMS-WAM WAVE-CURRENT MODEL
}

\author{
Rodolfo Bolanos ${ }^{1}$, Judith Wolf ${ }^{1}$, Jennifer Brown ${ }^{1}$, Pedro Osuna², Jaak \\ Monbaliu $^{3}$, Agustin Sanchez-Arcilla ${ }^{4}$.
}

\begin{abstract}
Ocean processes do not take place in isolation but interact with one another to form a complex system. This paper focuses on these processes by using and developing the POLCOMS-WAM model. The Stokes' drift and radiation stress effect on currents have been included, following state of the art formulations. The system is evaluated in the NW Mediterranean and the Irish Sea. Due to oceanographic properties of the Catalan coast, currents are typically less than $20 \mathrm{~cm} / \mathrm{s}$ and therefore the modification of waves due to the effect of currents is minimal. However, the wave induced currents, mainly caused by enhanced wind drag due to waves, produce a current of about the same magnitude as the ambient one and thus become an important source of mass transport. For the Irish Sea an improvement of storm surge modelling by considering a wave modified wind stress is presented.
\end{abstract}

\section{INTRODUCTION}

General circulation models are tools used to predict ocean circulation typically on an Eulerian reference and without resolving surface wind-waves and therefore do not consider wave effects. Ocean processes do not take place in isolation but interact with one another to form a complex system. Recently there have been a number of studies dealing with the construction of a theoretical framework for the wave-current interaction problem (Mellor 2005, Mellor 2003, Mellor and Blumberg 2004, Ardhuin et al. 2004, Rascle et al. 2006). Waves can be affected by the presence of currents due to refraction, modification of bottom drag and blocking. In the same way, currents can be modified by waves due to an increase in turbulence, Stokes drift, Langmuir circulation, radiation stress and indirectly by a modification of the wind stress. Mellor and Blumberg (2004) and Ardhuin and Jenkins (2006) showed the importance of waves on turbulence but also the effect of surface turbulence on wave dissipation. Weber et al. (2006) show the effect of the sea state dependent drag and Stokes drift on surge

\footnotetext{
${ }^{1}$ Proudman Oceanographic Laboratory, Joseph Proudman Building, 6 Brownlow Street, Liverpool L3 5DA, UK.

${ }^{2}$ CICESE, Km. 107 Carretera Tijuana - Ensenada C.P. 22860, Ensenada, B.C. México.

${ }^{3}$ Department of Civil Engineering, Katholieke Universiteit Leuven, Kasteelpark Arenberg 40, 3001 Heverlee, Belgium

${ }^{4}$ Laboratory of Maritime Engineering, Universidad Politecnica de Catalunya, Jordi Girona 13, Barcelona 08034, Spain.
} 
modeling. They also show the similarity of results of derivation of wave induced mass transport by Eulerian and Lagrangian approximation. Ardhuin et al. (2004) derived wave stress and mass flux effects on current momentum and mass equations showing the importance of the wave stresses. Jorda et al. (2007) performed a sensitivity study of the effect of Stokes drift and wave modified surface stress when simulating currents and dispersion of particles over the shelf.

Wave current interaction equations have been studied by Craik and Leibovich (1976), McWilliams and Restrepo (1999) among others. Mellor $(2003,2005)$ derive coupled current and wave equations in three dimensions assuming that the total current is a sum of ambient, wave-induced and turbulence terms taking into account the radiation stress, Stokes effect and Doppler velocity in order to develop a consistent equation for the coupled simulation of such processes.

This paper focuses on the development of the POLCOMS-WAM system in the framework of the EU MARIE project (http://lim050.upc.es/projects/marie), and its evaluation for the Mediterranean Sea and the Irish Sea. The main objectives of the paper are: a) to present the recent modifications introduced in POLCOMS-WAM model, b) to assess the implication of such modifications for the NW Mediterranean and c) Evaluate storm surge modeling in the Irish Sea.

\section{THE POLCOMS-WAM MODEL}

The coupled POLCOMS-WAM system has been under development at the Proudman Oceanographic Laboratory for the last 6 years. The POLCOMS (Proudman Oceanographic Laboratory Coastal-Ocean Modelling System) is a three dimensional primitive equation numerical model formulated in a spherical polar, terrain following coordinate system (sigma coordinates) and on a B-Grid. (Holt and James 2001). It solves the incompressible, hydrostatic, Boussinesq equation of motion divided into depth varying and depth independent parts to allow time splitting between barotropic and baroclinic components. The turbulence closure scheme uses Mellor and Yamada $(1974,1982)$ with a modification proposed by Craig and Banner (1994) to take into account surface wave breaking. The system has been structured to allow its execution on parallel and serial computers (Ashworth et al., 2004). 
The wave model used is the PRO-WAM model (Monbaliu et al., 2000). The model simulates the $2 \mathrm{D}$ wave spectral evolution considering the energy input by wind, energy dissipation by whitecapping, non-linear wave-wave interactions and bottom friction.

The POLCOMS and PRO-WAM models are coupled in a two way mode to consider several processes; taking into account the wave refraction by currents, bottom friction by currents and waves and enhanced wind drag due to waves. The wave current interaction module is prepared to allow the synchronous exchange of information between POLCOMS and WAM, WAM being embedded in the baroclinic step of the model. Data from POLCOMS to WAM include barotropic and bottom layer current components and water depth updated every baroclinic time step. Time interpolated wind components are also transferred from POLCOMS to WAM within a moving framework according to the barotropic current components (Osuna and Wolf 2005). The effect of the coupling at the bottom due to the presence of waves and currents is estimated using Madsen the (1994) formulation. Next we discuss the implementation of further interactions namely Stokes drift and radiation stress.

IMPLEMENTATION OF INTERACTION TERMS INTO THE POLCOMS-

WAM

\section{Stokes drift}

Stokes drift is a well known second order wave process describing the net transport due to waves. The behavior of the Stokes drift has been studied theoretically, measured and modelled in several ways. Rascle et al. (2006) studied the upper ocean dynamics showing an important surface shear due to the Stokes drift, the different Stokes drift estimations for sea and swell waves and the effect of the Stokes drift combined with the Coriolis force on Eulerian velocities over the whole water column, leading to current magnitudes of 20 $30 \%$ of the wind induced currents. Lewis and Belcher (2004) showed the effect of the Stokes drift in the Ekman layer, proving to be a better approximation when describing the angular deflections of the currents. Smith (2006) studied the effect of the Stokes drift from measurements with an Eulerian approach showing that the Stokes drift is intermittent and might be related to the groupiness of waves. 
The Stokes drift effects have been considered following the formulation of Mellor $(2003,2005)$ defining Stoke velocity for a 2D directional spectrum as:

$$
U_{s \alpha}=2 g \int_{\theta} \int_{\sigma} \frac{k_{\alpha}}{c} \frac{\cosh 2 k D(1+\varsigma)}{\sinh 2 D k D} F \partial \sigma \partial \theta
$$

where $k_{\alpha}$ represents the components of the wave number vector $\mathrm{k}$, c their respective celerity, D water depth, $\mathrm{F}(\sigma, \theta)$ the wave energy, $g$ acceleration due to gravity. $\varsigma$ is the vertical sigma coordinate system. $\theta$ and $\sigma$ are the direction and frequency of each spectral component.

\section{Radiation stress}

Longuet-Higgins and Stewart $(1962,1964)$ described the radiation stress of surface waves as an excess flux of momentum by the waves. Therefore the momentum conservation modifies the current field induced by the radiation stress. Its effects are more evident in shallow water due to energy flux gradients. Mellor (2003) worked out a formulation to explicitly take into account this process in ocean models. The expressions of Mellor were given for a monochromatic wave but they can be adapted so that a wave spectrum can be accounted for:

$$
\begin{aligned}
& S_{\alpha \beta}=\iint_{\theta \sigma} k D\left[\frac{k_{\alpha} k_{\beta}}{k^{2}} F_{C S} F_{C C}+\delta_{\alpha \beta}\left(F_{C S} F_{C C}-F_{S S} F_{C S}\right)\right] F \partial \partial \partial \theta \\
& S_{p \alpha}=\iint_{\theta \sigma} k D\left[\frac{F_{S S} \partial F}{2 \partial x_{\alpha}}+\left\{(1+\varsigma) F_{C S}-\frac{\cosh k D}{\sinh k D} F_{S S}\right\} F \frac{\partial k D}{\partial x_{\alpha}}\right]\left(F_{C C}-F_{S S}\right) \partial \partial \partial \theta
\end{aligned}
$$

where $\alpha, \beta$ are the horizontal component, $\delta_{\alpha \beta}=1$ for $\alpha=\beta$ and the depth dependent functions are defined as:

$$
\begin{aligned}
& F_{S S}=\frac{\sinh k D(1+\varsigma)}{\sinh k D} ; \quad F_{C S}=\frac{\cosh k D(1+\varsigma)}{\sinh k D} \\
& F_{S C}=\frac{\sinh k D(1+\varsigma)}{\cosh k D} ; \quad F_{C C}=\frac{\cosh k D(1+\varsigma)}{\cosh k D}
\end{aligned}
$$




\section{Wind-stress formulation}

Wind stress, $\tau$, depends on the air density, $\rho_{\mathrm{a}}$, and friction velocity $\left(\mathrm{u}_{*}\right)$, which is related to the wind speed at $10 \mathrm{~m}\left(\mathrm{U}_{10}\right)$, by $\mathrm{u}^{2}{ }^{2}=\mathrm{C}_{\mathrm{D}}\left(\mathrm{U}_{10}\right)^{2}$, where $\mathrm{C}_{\mathrm{D}}$ is the drag coefficient (Janssen, 2004):

$$
\tau=\rho_{a} u_{*}^{2}=\rho_{a} C_{D} u_{10}^{2}
$$

To correctly model the wind-stress an appropriate roughness length $z_{0}$ is predicted using Charnock's (1955) method, based on dimensional grounds. The roughness length is scaled by the acceleration of gravity $(\mathrm{g})$ and $\mathrm{u}$ *:

$$
z_{0}=\frac{\alpha u_{*}^{2}}{g}
$$

The Charnock parameter, $\alpha$, is thought to be related to wave-age (Janssen, 2004). Although $\alpha=0.0185$ seems to provide accurate representation of the surface stress for all sea states (Wu, 1982), a larger value is imposed for young (steep) wind-seas due to increased wave-wind coupling (for details see Janssen, 1991) in WAM. In WAM $\alpha$ is 'wave-age' dependent, thus varies in time and space. For compatibility with the wave model a Charnock relation has now been implemented into POLCOMS, in which the surface roughness length, $z_{0}$, is provided by the wave model, thus using the same wind-stress for wave and ocean modelling.

\section{STUDY AREAS AND MODEL SETTINGS}

\section{The NW Mediterranean}

The North-Western Mediterranean (Fig. 1) is a semi-enclosed sea characterized by large depth gradients. The Catalan-Spanish coast is located within the NW Mediterranean, and it has a narrow continental shelf in the north and a widening at the south with the presence of the Ebro delta. It is a microtidal environment characterized by a slope current (continuation of the Northern Current, Millot (1999)) of the order of $20-30 \mathrm{~cm} / \mathrm{s}$. Sea level variations are mainly due to atmospheric forcing. Wave climate is mild with a yearly mean of 
about $0.8 \mathrm{~m}$ but significant wave heights can reach more than $6 \mathrm{~m}$ in severe storm conditions.

The POLCOMS-WAM was implemented for the NW Mediterranean Sea with a spatial resolution of 0.1 degree from $5^{\mathrm{O}} \mathrm{W}$ to $18^{\mathrm{O}} \mathrm{E}$ longitude and $34^{\mathrm{O}} \mathrm{N}$ to $45^{\mathrm{O}} \mathrm{N}$ latitude (Fig. 1) with 20 sigma levels. Initial temperature and salinity conditions are taken from climatological data with a resolution of 0.25 degree and 35 vertical levels based on the MEDATLAS data bank using the MODB analysis technique (www.bo.ingv.it/mfstep/WP8/clim_data.htm) and therefore a $3 \mathrm{D}$ interpolation was necessary also taking account the terrain following coordinate system of POLCOMS. For the vertical distribution and due to the large depth found in the Mediterranean, a modification of the sigma coordinates (S coordinates) was used that allows an increased vertical resolution at the surface. Atmospheric forcing was by surface wind stress assuming constant atmospheric pressure, humidity and temperature. From an operational and validation point of view these settings may produce errors due to the coarse representation of initial conditions, the atmospheric forcing boundary conditions, but for the assessment of the effects of the various terms for reliable conditions they proved to be sufficient. Note that WAM was run with a spectral resolution of 25 frequencies and 24 directions.

The system was run for 30 days as a spin up period with wind velocity set to zero. Then the system was forced by winds from the atmospheric model MASS that has been used and validated for wave modelling in the Mediterranean (Bolaños et al. 2007) for the November 2001 period. During this period there occurred a severe storm that affected the whole NW Mediterranean and in particular the Catalan coast during about 10 days. Significant wave height reached about $8 \mathrm{~m}$ in the NW Mediterranean and $6 \mathrm{~m}$ at the Catalan coast. 

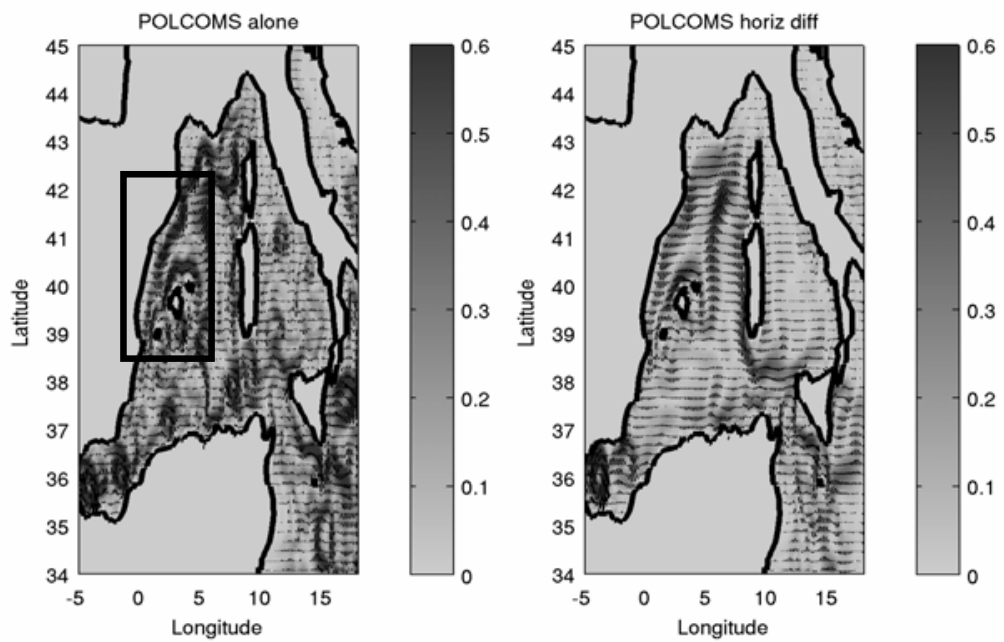

Figure 1. NW Mediterranean. Left panel shows the surface currents when using POLCOMS alone. Right panel shows the currents of POLCOMS stand alone considering horizontal diffusion. Gray scale represents velocity in $\mathrm{m} / \mathrm{s}$. Square on the left panel shows the location of the Catalan coast.

\section{The Irish Sea}

The POLCOMS-WAM was also implemented in the Irish Sea (Fig. 2) for storm surge modeling. To include the influence of externally generated waves propagating into the study area, a one-way nested model approach has been set up as follows. A $1^{\circ}$ North Atlantic WAM model forces the boundary of a 1.85 $\mathrm{km}$ Irish Sea model. To capture the external surge effects generated outside of the Irish Sea a one-way nested approach from the Operational Continental Shelf Surge model at Proudman. The tide-surge model provides hourly, $1 / 9^{\circ}$ by $1 / 6^{\circ}$ forcing to the $1.85 \mathrm{~km}$ Irish Sea model. The Proudman Oceanographic Laboratory Coastal Ocean Modelling System (POLCOMS, Holt and James, $2001)$ then simulates the internal surge using the 15 constituents available (Q1, O1, P1, S1, K1, 2N2, MU2, N2, NU2, M2, L2, T2, S2, K2 and M4). Hourly wind and pressure data were provided by the UK Met Office North East Atlantic model, with a resolution of $1 / 9^{\circ}$ by $1 / 6^{\circ}(\sim 12 \mathrm{~km})$ to drive the models.

For the Irish Sea model wave-tide-surge interaction has been taken into account by 2-way coupling of POLCOMS and WAM. The coupling is achieved through the surface and bottom stress and wave refraction due to the presence of time varying current and elevation fields (Wolf et al., 2002). In the POLCOMS- 
WAM model the minimum water depth was set to $5 \mathrm{~m}$. The predicted surge elevation is defined as the residual water level i.e. difference between the total elevation and the tidal elevation (from the model).

The modeled period is in January 2007 when a large storm surge occurred due a depression traveling east to the north of Ireland and across Scotland on the 18th. This caused $12 \mathrm{~m} / \mathrm{s}$ south westerly winds in the Irish Sea that increased in intensity to $18 \mathrm{~m} / \mathrm{s}$ and veered to the west reaching velocities of $22 \mathrm{~m} / \mathrm{s}$ before dying away. The tide was mid-way into the spring tidal phase in Liverpool Bay and the waves reached a peak height of $4.9 \mathrm{~m}$ with a peak period of $11.4 \mathrm{~s}$.

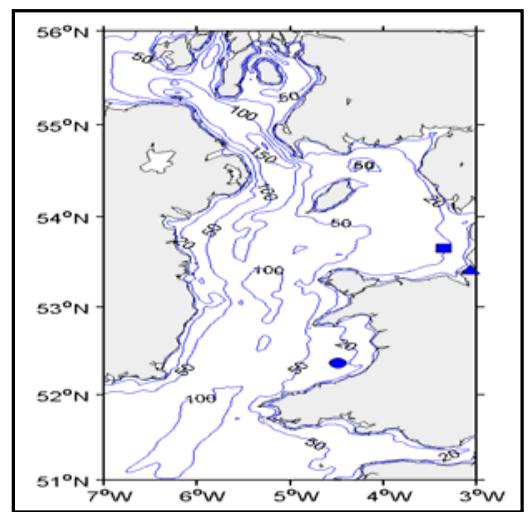

Figure 2. Irish Sea bathymetry. Triangle shows location of the sea level data and square shows location of wave buoy.

\section{RESULTS}

Figure 1 shows the results of runs of POLCOMS alone with and without considering horizontal diffusion. The qualitative analysis of the POLCOMS performance for the NW Mediterranean and in particular the Catalan coast is acceptable for the surface and barotropic current field. The model is able to produce a continental slope current that flows from NE along the Catalan coast. It is possible to observe some mesoscale features that are common in the area. The present configuration produces discontinuities at the east boundary and large velocities at some locations in the inner domain are present. The inclusion of horizontal diffusion reduces the somewhat high velocities and the main pattern of the Northern current is conserved, but it also reduces the eddy structures. A qualitative comparison with the general properties of surface 
currents in the Mediterranean (Millot, 1999) shows that POLCOMS is able to reproduce these properties and thus its results are considered valid for a sensitivity analysis.

Figure 3 shows a comparison of the time averaged surface current for 3 different runs. The consideration of all wave processes in the model produces a slight change in the current magnitude but it is not as important as horizontal diffusion. The horizontal diffusion, as shown in Figure 1 and Figure 3, not only reduces velocity but also the eddy structures.
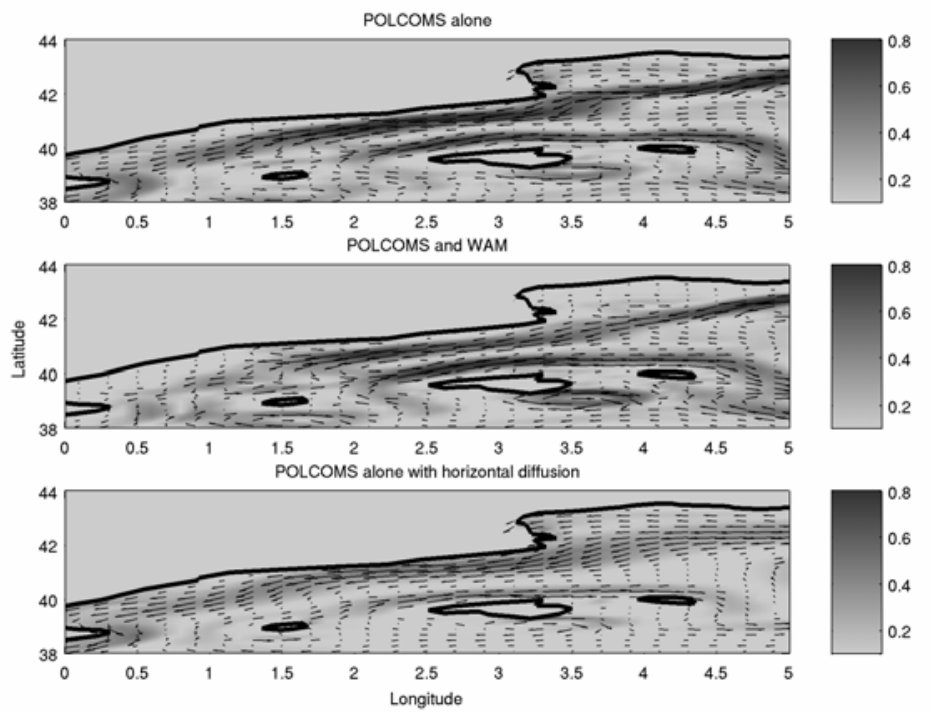

Figure 3. Comparison of surface currents at the Catalan coast for the case of POLCOMS alone (Top panel), POLCOMS-WAM (Centre panel) and POLCOMS with horizontal diffusion (Bottom panel). Gray scale represent velocity in $\mathrm{m} / \mathrm{s}$.

Figures 4 and 5 show a comparison of mean surface salinity and temperature distributions. The salinity field is more affected by horizontal diffusion while temperature is more affected by atmospheric forcing indicating that there is no balance between air and sea temperature (effect of the constant air temperature used). For both fields, the wave effects are small compared to 
other terms. From all the wave effects considered the principal one is the modified wind stress.
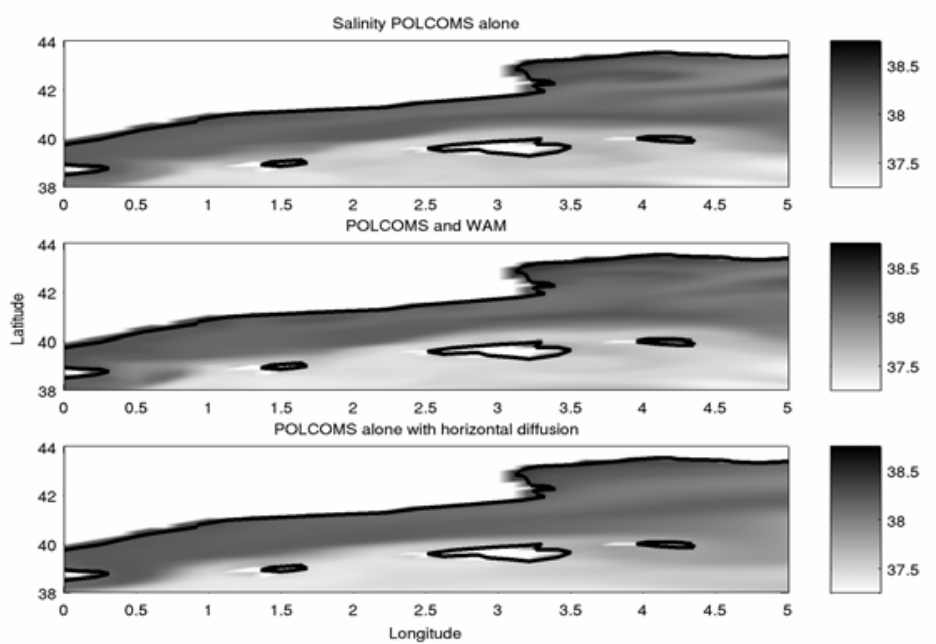

Figure 4. Comparison of mean surface salinity distribution for same runs as figure 3.
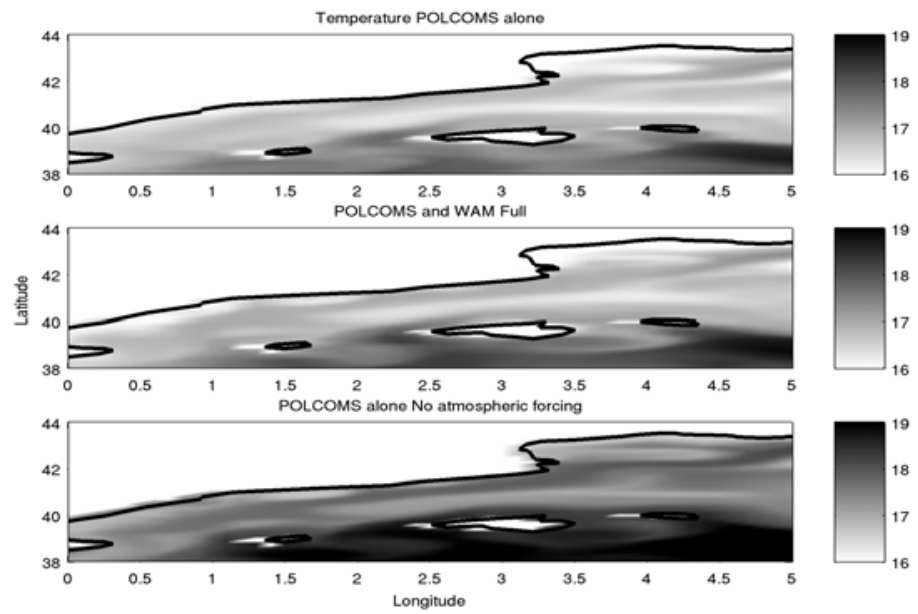

Figure 5. Comparison of mean surface temperature distribution. Top panel is POLCOMS alone, centre is POLCOMS -WAM and bottom panel is POLCOMS without atmospheric forcing. Gray scale represent temperature in $\mathrm{C}^{\circ}$. 
The 2007 surge hindcast (Fig. 6) in the Irish Sea has shown, for this case, that implementing the wave dependent wind stress is more accurate at capturing the surge peak than using a constant Charnock parameter. In this case the constant value was taken as that imposed in the Proudman Operational Surge model ( $\alpha=0.0275$, Williams and Flather, 2000). This result agrees with the results presented by Mastenbroek et al. (1993).

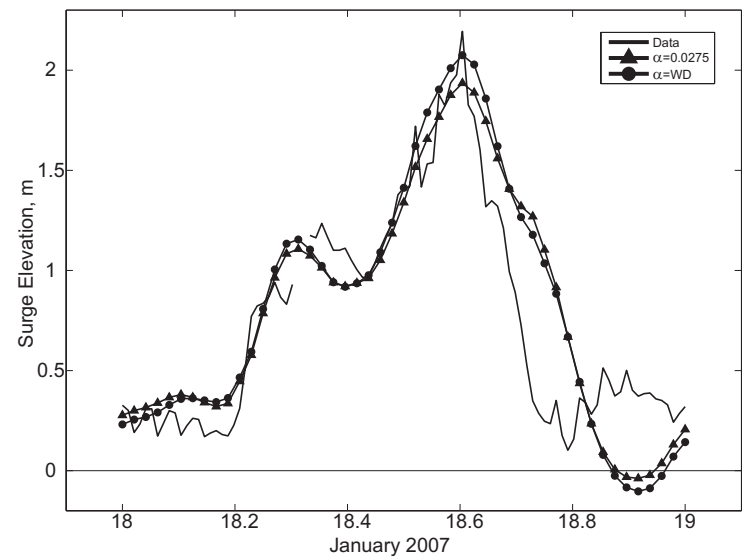

Figure 6. Comparison of surge data (solid line) and model hindcast for a constant Charnock parameter of 0.0275 (triangular marked line) and for a wave dependent Charnock parameter (dotted marked line) at Hilbre tide gauge.

\section{DISCUSSION}

These results show that POLCOMS can be used for proper ocean circulation modelling in the NW Mediterranean and that the settings chosen are acceptable to perform an evaluation of the different forcing terms. Further effort is needed for a full validation of the model, increasing spatial resolution, and probably extending the domain to the full Mediterranean in order to avoid open boundary problems. The Northern current appears to be very persistent but the proper prediction might be influenced by the spatial resolution in order to resolve the continental slope accurately.

Even though direct wave effects (Stokes drift and radiation stress) are one of the main information gaps in ocean models, these runs showed that their 
effects are of second order compared to others. The main wave effect was an "indirect" one due to the modified wind stress and $\mathrm{z}_{0}$.

For the NW Mediterranean (a mostly deep area) the main "direct" effect was due to Stokes drift which modifies the surface currents and this has an impact on the distribution of temperature and salinity. Here, we have to point out that we are missing the direct effect of waves on turbulence. This panorama might change at shallow/intermediate water where bottom friction and wave breaking (even without wind at all) can induce extra momentum and mixing.

Ardhuin et al. (2007) showed some inconsistency from the derivation of Mellor (2003 and 2005) mainly due to the assumptions of a flat bottom and Airy waves. Such errors must be more evident in shallow and steep bottom areas where radiation stress has an important effect. The Stokes drift term in deep water is, in general sense, very similar and deviations are likely negligible compared to errors due to, for example, vertical resolution. Ardhuin et al. (2008) presented an explicit formulation for the ocean and wave couplings considering sloping bottoms and non-linear waves. Apart from the Stokes drift that modifies the Coriolis term (wave pseudomomentum), they also derive two new wave dependent pressure wave terms. One term $\left(\mathrm{S}_{\mathrm{j}}\right)$ is depth uniform and approximates to zero for deep water. The second term $\left(\mathrm{S}_{\text {shear }}\right)$ takes into account the interaction of waves with the shear of currents and it is of second order compared to $\mathrm{S}_{\mathrm{j}}$. Therefore, for the NW Mediterranean (deep areas), both radiation stress and pressure terms can be neglected. This statement might change for other areas such as the Irish Sea where the bathymetric gradients and the shallow water processes would be more important.

It is well known that open boundaries are a cause of inconsistencies in ocean models and therefore many people have paid some attention to this (Lavelle and Thacker, 2008). A proper study of the effect of the boundary conditions for the NW Mediterranean setting requires more tests with different boundary properties. For validation purposes an improvement of the boundaries will be required. From the tests done it seems that the boundaries have some local effect but they do not produce any large inconsistent values and the inner part of the domain does not seem to be very affected.

The possible overestimation of currents by the reference run (POLCOMS alone without horizontal diffusion) might produce an underestimation of the 
wave effects in the Mediterranean, this should be validated against field observation to support a proper calibration of the horizontal diffusion coefficient.

\section{ACKNOWLEDGMENTS}

The authors thank the MARIE EU project (MTKD-CT-2004-014509). Authors also thank Fabrice Ardhuin for useful comments and discussion.

\section{REFERNCES}

Ardhuin, F. and Jenkins, A. D. 2006. On the interaction of surface waves and the upper ocean turbulence. Journal of Physical Oceanography, 36, 551557.

Ardhuin, F., B. Chapron and T. Elfouhaily, 2004, Waves and the air-sea momentum budget: Implications for ocean circulation modeling, Journal of Physical Oceanography, 34(7), 1741-1755

Ardhuin, F., Jenkins, A.D. and Belibassakis, K.A., 2007. Commentary on "The three dimensional current and surface wave equations" by George Mellor. Journal of Physical Oceanography, JPO-3670.

Ardhuin, F., Rascle, N., and Belibassakis, K.A., 2008. Explicit wave-averaged primitive equations using a generalized Lagrangian mean. Ocean Modelling, 20, 35-60

Ashworth, M., Holt, J.T., Proctor, R., 2004. Optimization of the POLCOMS hydrodynamic code for terascale high-performance computers. Proceedings of the $18^{\text {th }}$ International parallel and distributed processing symposium, $26^{\text {th }}-30^{\text {th }}$ April, Santa Fe, Ne Mexico.

Bolaños, R., Sánchez-Arcilla, A., Cateura, J., 2007. Evaluation of two atmospheric models for wind-wave modelling in the NW Mediterranean. Journal of Marine Systems. 65, 336-353.

Charnock, H. 1955. Wind-stress on a water surface. Quarterly Journal of the Royal Meteorological Society, 81(350), 639-640.

Craig, P.D. and Banner, M.L., 1994. Modeling wave-enhanced turbulence in the ocean surface layer. Journal of Physical Oceanography, 24, 2546-2559.

Craik, A.D.D., and Leibovich, 1976. A rational theory for langmuir circulation. Journal of Fluid Mechanics, 73, 401-426. 
Holt, J.T. and James, I.A. 2001. An S coordinate density evolving model of the northwest European continental shelf 1, Model description and density structure. Journal of Geophysical Research, Vol, 106, No. C7, 1401514034.

Janssen, P.A.E.M. 2004. The interaction of ocean waves and wind. Cambridge University Press, Cambridge, 300pp.

Janssen, P.A.E.M., 1991. Quasi-linear theory of wind generation applied to wave forecasting, Journal of Physical Oceanography, 21 1631-1642

Jorda, G., Bolaños, R., Espino, M. and Sanchez-Arcilla, A. 2007. Assessment of the importante of the current-wave coupling in the shelf ocean forecast. Ocean Science. In press.

Lavelle and Thacker, 2008. A pretty good sponge: dealing with open boundaries in limited-area ocean models, Ocean Modelling. 20 (2008), pp. 270-292.

Lewis, D.M., and Belcher, S.E. 2004. Time-dependent, coupled, Ekman boundary layer solutions incorporating Stokes drift. Dynamics of atmospheres and oceans, 37, 313-351.

Longuet-Higgins, M.S. and Stewart R.W. 1962. Radiation stress and mass transport in gravity waves with application to surf 'beats'. Journal of Fluid Mechanics, 13, 481-504

Longuet-Higgins, M.S. and Stewart R.W. 1964. Radiation stress in water waves; a physical discussion with applications. Deep-Sea Research., 11, 529-562.

Madsen, O.S., 1994. Spectral wave-current bottom boundary layers flows. Proc $24^{\text {th }}$ ICCE. ASCE 1, 384-398.

Mastenbroek, C., Burgers, G and Janssen, P.A.E.M. 1993. The dynamical coupling of a wave model and a storm surge model through the atmospheric boundary layer. Journal of Physical Oceanography, 23, 1856-1866.

McWilliams, J.C., and Restrepo, J.M., 1999. The wave-driven ocean circulation. Journal of Physical Oceanography, 29, 2523-2540.

Mellor, G. and Blumberg, A., 2004. Wave breaking and ocean surface layer thermal response. Journal of Physical Oceanography, 34, Notes and correspondence, 693-694.

Mellor, G., 2003. The three-dimensional current and surface wave equations. Journal of Physical Oceanography, 33, 1978-1989

Mellor, G., 2005. Some consequences of the three-dimensional current and surface wave equations. Journal of Physical Oceanography, 35, 2291-2298. 
Mellor, G.L. and Yamada, T., 1982. Development of a turbulence closure model for geophysical fluid problems. Review of geophysics and Space Physics, 20, No. 4, 851-875.

Millot, C. 1999. Circulation in the Western Mediterranean Sea. Journal of Marine Systems, 20, 423-442.

Monbaliu, J, Padilla-Hernández, R., Hargreaves, J., Carretero, J.C., Weimin, L., Sclavo, M., Gunther, H., 2000. The spectral wave model, WAM adapted for aplications with high spatial resolution. Coastal Engineering 41, 41-62

Osuna, P. and Wolf, J., 2005. A numerical study of the effect of wave-current interaction processes in the hidrodynamics of the Irish Sea. Proc. $5^{\text {th }}$ Int. Conf. on Ocean Wave and Analysis, WAVES2005. Madrid, Spain

Rascle, N., F. Ardhuin and E. A. Terray, 2006. Drift and mixing under the ocean surface: A coherent one-dimensional description with application to unstratified conditions, Journal of Geophysical Research-Oceans, 111(C3),

Smith, J.A. 2006. Observed variability of ocean wave Stokes drift, and the eulerian response to passing groups. Journal of Physical Oceanography, 36, 1381-1402.

Weber, J.A.H., Brostrom, G. and Saetra, O., 2006. Eulerian versus Lagrangian approaches to the wave-induced transport in the upper ocean. Journal of Physical Oceanography, 36, 2106-2118

Williams, J.A., Flather, R.A. 2000. Interfacing the operational storm surge model to a new mesoscale atmospheric model. POL Internal Document no. 127, Proudman Oceanographic Laboratory, Liverpool. 18pp.

Wolf, J., Wakelin, S.L., Holt, J.T. 2002. A coupled model of waves and currents in the Irish Sea. Proceedings of the Twelfth International Offshore and Polar Engineering Conference, Kitakyushu, Japan, 3, 108-114.

Wu, J. 1982. Wind-Stress Coefficients Over Sea Surface From Breeze to Hurricane. Journal Geophysical Research, 87(C12): 9704-9706. 
KEYWORDS - ICCE 2008

Comparison of wave-current interaction formulation using the polcoms-wam wave-current model

Rodolfo Bolanos, Judith Wolf, Jenny Brown, Pedro Osuna, Jaak Monbaliu, Agustin Sanchez-Arcilla

Abstract number: 11

Wave modeling

Ocean modeling

POLCOMS

WAM

Mediterranean

Irish Sea

Wave-current interaction

Wave storms

Storm surge 